\title{
Urinary tract infection in women of rural population of Haryana: a rising problem
}

\author{
Geetika Arora*, Parminder Kaur, Divya Agrawal
}

Department of Obstetrics and Gynecology, Adesh Medical College, Mohri, Kurukshetra, Haryana, India

Received: 26 September 2016

Revised: 06 October 2016

Accepted: 24 October 2016

\section{*Correspondence:}

Dr. Geetika Arora,

E-mail: drgeetsarora@rediffmail.com

Copyright: () the author(s), publisher and licensee Medip Academy. This is an open-access article distributed under the terms of the Creative Commons Attribution Non-Commercial License, which permits unrestricted non-commercial use, distribution, and reproduction in any medium, provided the original work is properly cited.

\begin{abstract}
Background: The study was aimed to understand the clinico-pathological characteristics of urinary tract infection along with the techniques used in diagnosis and treatment of the presenting infection. The study takes into consideration the various risk factors such as age, marital, socioeconomic status which influences the risk of having UTI.

Methods: The study was conducted in Adesh Medical College, Mohri district. A questionnaire was prepared in accordance to evaluate risk factors of urinary tract infection. The patients under study were chosen according to specific inclusion criteria. The patients presenting with symptoms of UTI were subjected to examination and then urine culture and sensitivity test. The uropathogens were isolated with the help of biochemical testing.

Results: Out of 500 women who atteneded gynae opd of Adesh Medical College, Mohri district were taken into study out of 500 patients 296 patients showed positive culture. UTI was found more in married females which were illiterate and belonged to low socioeconomic group. E.coli was the most common organism which was cultured. E.coli $(55 \%)$ was found to be the most prevalent organism followed by Klebsiella.

Conclusions: UTIs are some of the most common bacterial infections in women. Women with UTI need to be properly investigated by urinalysis and urine culture. Marital status, socioeconomic status has high impact on the lifetime risk for UTI. E.coli was found to be the most common cause of UTI in all the age groups.
\end{abstract}

Keywords: Haryana, Rural population, Uropathogens, Urinary tract infection

\section{INTRODUCTION}

Urinary tract infection (UTI) is the third most common infection experienced by humans after respiratory and gastro-intestinal infections. ${ }^{1}$ Although the urinary tract is normaly free of bacterial growth, bacteria that generally ascend from the rectal reservoir may cause UTI. Careful diagnosis and treatment results in successful resolution of infections in most cases. ${ }^{2}$ UTI is defined as the presence of 100000 or more colony forming units (CFU) per ml of urine. This Kass criteria has been questioned and bacterial counts of 10 or more organism per ml particularly when accompanied by pyuria $\left(>10 \mathrm{wbc} / \mathrm{mm}^{3}\right)$ provide impressive evidence of urinary tract infection in symptomatic young women., ${ }^{3,4}$ The Infectious Disease Society of America (IDSA) gave a slightly more relaxed consensus definition requiring 10 organisms per $\mathrm{ml}$ to diagnose cystitis and 10 per $\mathrm{ml}$ for pyelonephritiss. ${ }^{3-5}$

It is observed in India that UTI accounts for nearly 7 million office visits and 1 million emergency department visits, resulting in about 100,000 hospitalizations. ${ }^{6}$ Nevertheless, it is difficult to accurately assess the incidence of UTIs, because they are not reportable diseases in India and many other countries such as the United States. This situation is further complicated by the 
fact that accurate diagnosis depends on both the presence of symptoms and a positive urine culture, although in most outpatient settings this diagnosis is made without the benefit of culture.

Women are significantly more likely to experience UTI than men. Nearly 1 in 3 women will have had at least 1 episode of UTI requiring antimicrobial therapy by the age of 24 years. Almost half of all women will experience UTI during their lifetime. ${ }^{7}$ This is because of short urethra, its proximity to vagina and anus and inability of women to empty their bladder completely. High incidence is seen in lower socioeconomic group sexual activity and certain contraceptive methods are also said to increase the risk.

Viller et al had observed that approximately 4 percent of the adult females had bacteriuria and were asymptomatic; 10-29 percent of the entire female population was calculated to experience urinary tract infection at some time during their life and 40 percent of the patients with asymptomatic bacteriuria in early pregnancy and later on developed acute pyelonephritis. ${ }^{8}$

Clinical manifestations may vary from asymptomatic bacterial colonization of the bladder to irritative symptoms such as frequency and urgency associated with bacterial infection; upper tract infections associated with fever, chills and flank pain; and bacteremia associated with severe morbidity, including sepsis and death. Although the vast majority of patients respond promptly and are cured by therapy, early identification and treatment of patients with complicated infections that place them at significant risk, remains a clinical challenge to urologists. ${ }^{9}$

\section{METHODS}

The present study was carried out in Adesh Medical College, Department of obstetrics and gynaecology.500 female patients attending OPD from September 2015 to August 2016 with any complaint pointing towards UTI were included in study.

The selection of patients was made on the basis of the history of an episode of urinary tract infection clinically and/or bacteriologically diagnosed. Care was taken that the patients selected did not suffer from medical diseases like glomerulonephritis, diabetes, neurogenic bladder and gynaecological disorders as these could secondarily aggravate the existing urinary tract infection. Pregnant females were also not included in this study. Verbal informed consent was obtained from each woman before the commencement of the research.

Using standard questionnaires patients were asked about Socio-demographic data such as age, occupation, marital status, parity, past history of infection ,age related complications and symptoms such as frequency of micturation, retention of urine, burning micturation, fever and chills and this information was kept confidential during the research.

Each patient who gave a history indicative of urinary tract infection was clinically examined and investigated in detail A clean-catch midstream specimen or suprapubic aspirate, in subjects who were unable to give the former, was collected in a sterile wide-mouth leakproof container to hold about $50 \mathrm{ml}$ specimen. A standard loop technique (CLSI, 2011) was used to place $0.01 \mathrm{ml}$ of urine for inoculation on CLED agar at $37^{\circ} \mathrm{C}$ for 24 hours and extended up to 48 hours in cases of no growth of any organism. The number of colonies was counted to quantify the organism. The diagnosis of UTI was made based on the significant colony count of a single pathogen like $>105 \mathrm{CFU} / \mathrm{ml}$ for gram negative bacteria (GNB) and $>104 \mathrm{CFU} / \mathrm{ml}$ for a Gram positive bacteria (GPB). The organisms were identified by following the general biochemical tests like catalase test, oxidase test, triple sugar iron agar (TSI) test, citrate utilization test (Simmon's citrates medium), urease test (Christensen's Urea Agar), indole motility $\mathrm{H} 2 \mathrm{~S}$ production test (sulphide indole motility medium).

Centrifuged urine deposit was examined microscopically at high magnification for pus cells, red blood cells, epithelial cells, casts, crystals, yeast-like cells. Pus cells $>5 / \mathrm{HPF}$ were also considered significant for infection

Isolated colonies are identified in a systematic way: microscopic examination after Gram staining to differentiate between gram negative and gram positive bacteria. The Gram-positive and Gram-negative organisms were culture isolates which were further identified by using various biochemical reactions up to genus/species levels wherever applicable. For Gram negative organisms: Sugar fermentation test, Indole test, Oxidase test, Methyl Red test, and urease test. For Gram positive organisms: coagulase test and catalase test nutrient agar, blood agar and MacConkey's medium are the frequently used growth media for urine cultures.

\section{RESULTS}

Of the 500 urine samples examined in this study, 296 were found to contain significant bacteriuria.

Table 1: Age distribution of the 296 patients with UTI.

\begin{tabular}{|l|l|}
\hline Age & No. of patients \\
\hline $0-10$ & 10 \\
\hline $11-20$ & 20 \\
\hline $21-30$ & 68 \\
\hline $31-40$ & 45 \\
\hline $41-50$ & 28 \\
\hline $51-60$ & 55 \\
\hline $61-70$ & 36 \\
\hline $71-80$ & 34 \\
\hline
\end{tabular}


Table 2: Frequency of other UTI related significant factors.

\begin{tabular}{|lll|}
\hline \multirow{2}{*}{ Factors } & & $\%$ of Bacteriuria \\
\hline \multirow{2}{*}{ Education } & Good & 30 \\
\cline { 2 - 3 } & Poor & 70 \\
\hline \multirow{2}{*}{ Past h/o UTI } & Illiterate & 85 \\
\cline { 2 - 3 } & Educated & 15 \\
\hline \multirow{2}{*}{ Sexual activity } & Yes & 80 \\
\cline { 2 - 3 } & No & 20 \\
\cline { 2 - 3 } & Active & 70 \\
\hline
\end{tabular}

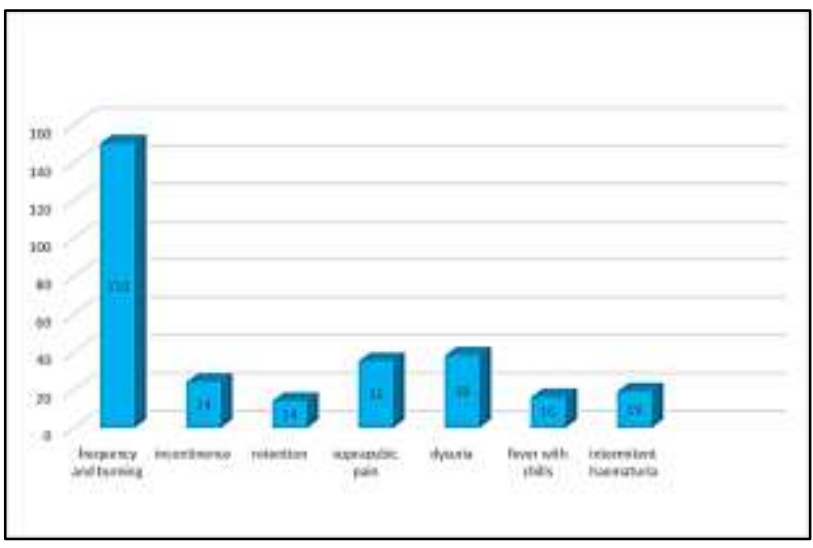

Figure 3: Frequency of various symptoms associated with UTI.

Table 4: Frequency of various pathogenic organisms in study.

\begin{tabular}{|lll|}
\hline Organisms & Number & $\%$ \\
\hline Stap saprophyticus & 6 & 2 \\
\hline Citrobacter & 3 & 1 \\
\hline Enterobacter & 15 & 5 \\
\hline Enterococcus & 24 & 8 \\
\hline E. coli & 162 & 55 \\
\hline Coagulase neg staph & 6 & 2 \\
\hline Klebsiella & 30 & 10 \\
\hline Proteus & 12 & 4 \\
\hline Psuedomonas & 24 & 8 \\
\hline Staphylococcus aureus & 5 & 2 \\
\hline Candida albicans & 9 & 3 \\
\hline
\end{tabular}

\section{DISCUSSION}

Our study was carried out in outpatient's patients. 296 patients out of 500 showed a positive growth in culture. The prevalence of culture proven UTI was $42 \%$.this was higher than prevalence rate of $31.35 \%$ significant bacteriuria recorded by Savitha $\mathrm{T}$ et al and lower than $66.67 \%$ as recorded by Mahesh $\mathrm{E}$ et al. The wide variation in the prevalence rate among different population may be due to factors like sexual intercourse, peer group influence, pregnancy, low socio-economic status. Women are particularly at risk of developing UTIs because of their short urethra, and certain behavioral factors which include delay in micturition, sexual activity and the use of diaphragms and spermicides which promote colonization of the periurethral area with coliform bacteria. Infection in women most often results from perineal or periurethral bacteria that enter the urethra and ascend into the bladder, often in association with sexual activity, or due to mechanical instrumentation such as catheterization. ${ }^{10}$

This disease was most commonly seen in 2nd and 3rd decade of life. A further increase in incidence was seen beyond 50 years of age. Rates of infection are high in postmenopausal women because of bladder or uterine prolapse causing incomplete bladder emptying; loss of estrogen with attendant changes in vaginal flora (notably, loss of lactobacilli), which allows periurethral colonization with gramnegative aerobes, such as Escherichia coli; and higher likelihood of concomitant medical illness, such as diabetes. ${ }^{11}$

It will be noted that 70 percent of the females included were married, while unmarried females constituted the remaining 30 percent. This was in consistent with a study by Susan AMK who concluded that most uncomplicated urinary tract infections occur in women who are sexually active. $^{12}$

There is high incidence of symptomatic UTI necessitating antimicrobial therapy, as well as an increasing population of highly susceptible patients who require antimicrobials for UTI and/or other infections, resulting in an increased risk of developing antimicrobial resistance among common uro-pathogens. As a result, there is a growing need to ensure appropriate therapy with agents that maximize success for both community-acquired and nosocomial UTI while minimizing risk of the development of antimicrobial resistance.

96 patients belonged to middle class families and 200 patients were from poor section of the community. A study conducted by Shilpi et al, in central India quoted lower urinary tract symptoms (LUTS) is commonly found in females of low socio-economic status. ${ }^{13}$ Malnutrition, poor hygiene, low socioeconomic status are associated with UTI and these factors are more in rural settings. $^{14}$

Regarding the causative agent mainly Gram negative bacteria belonging to Enterobacteriaceae were isolated from urine samples of women. The most predominant uropathogen was Escherichia coli accounting for 55\% was seen in our study in comparison to most frequently isolated organism in Britain (65.1\%) and in US studies by Sahm et al. ${ }^{19}$ This finding is similar to other reports which suggest that gram negative bacteria, particularly E.coli are the commonest pathogens isolated from patients with UTI. $^{20}$ The incidence of E.coli in our study was higher when compared with the Nigerian studies reporting $42.10 \%$ and $51 \% .^{15,34}$ Most of the studies conducted in 
Africa and Arab countries showed less than 50\% isolation of E coli from the UTI patients but re- ported a higher percentage $(29 \%)$ of $S$. aureus as second most frequently isolated bacteria from UTI cases. Reports from other developing or developed countries were the isolation of Gram positive bacteria as uropathogen is very low $<10 \%$. $^{16-18}$ The second commonest uropathogen isolated in our study was Klebsiella species (10\%), Enterococcus species (8\%), Puedomonas (8\%), Proteus sp. (4\%). This was similar to other studies. ${ }^{21-25}$ Other pathogens isolated were Enterobacter (5\%), C. albicans (3\%), S. aureus (2\%), Citrobacter (1\%). In contrast to this finding, one study from Aurangabad showed Klebsiella as the most common isolate followed by Escherichia coli, Pseudomonas aeruginosa and Staphylococcus aureus. ${ }^{26}$

\section{CONCLUSION}

UTIs are some of the most common bacterial infections in women. UTIs are mainly caused by reinfection by same pathogen. Women with UTI need to be properly investigated by urinalysis and urine culture .Marital status; socioeconomic status has high impact on the lifetime risk for UTI. E.coli was found to be the most common cause of UTI in all the age groups.

\section{Funding: No funding sources}

Conflict of interest: None declared

Ethical approval: The study was approved by the Institutional Ethics Committee

\section{REFERENCES}

1. Pushpalatha KS. Urinary tract infection and management. J Nighting Nursing Times. 2008;4(5):28-32.

2. Kansal R. Study of cases of urinary tract infection in rural population. Int $\mathrm{J}$ Pharm Med Res. 2014;2(4);113-5.

3. Kass EH. Asymptomatic infections of the urinary tract. Trans Assoc Am Physicians. 1956;69:56-64.

4. Stamm WE, Counts GW, Running KR, Fihn S, Turck M, Holmes KK. Diagnosis of coliform infection in acutely dysuria women. N Engl J Med. 1982;307:463-8.

5. Hooton TM, Stamm WE. Diagnosis and treatment of uncomplicated urinary tract infection. Infect Dis Clin North Am. 1997;11:551-81.

6. Gulati S, Kher V, Gupta A, Arora P, Rai PK, Sharma RK. Spectrum of Infections in Indian Children with Nephrotic Syndrome. Pediatr Nephrol. 1995;9:431-4.

7. Kunin CM. Urinary tract infections in females. Clin Infect Dis. 1995;18:1-12.

8. Villar J, Lydon-Rochelle MT, Gülmezoglu AM, Roganti A. Duration of treatment for asymptomatic bacteriuria during pregnancy. Cochr Database Syst Rev. 2000;CD000491.

9. Najar MS, Saldanha CL, Banday KA. Approach to urinary tract infections. Indian $\mathrm{J}$ Nephrol. 2009;19(4):129-39.
10. Litza JA, Brill JR. Urinary tract infections. Prim Care. 2010;37(3):491-507.

11. Hotchandani R, Aggarwal KK. Urinary tract infections in women. Indian $\mathrm{J}$ Clin Pract. 2012;23(4):187-92.

12. Susan AMK. Diagnosis and management of uncomplicated urinary tract infections. American Family Physician. 2005;72(3):451-6.

13. Shilpi G, Onkar S, Sapna S, Raj KM. Epidemiology, perception and treatment of females presenting with lower urinary tract symptoms at a government hospital in central India. The Internet Journal of Surgery. 2008;21(1).

14. Oladeinde BH, Omoregie R, Olley M, Anunibe JA. Urinary tract infection in a rural community of Nigeria. North American J Med Sci. 2011;3(2):75-7.

15. Okonko IO, Ijandipe LA, Ilusanya OA. Incidence of urinary tract infection (UTI) among pregnant women in Ibadan, South-Western Nigeria. African J Biotech. 2009;8(23):6649-57.

16. Akram M, Shahid M, Khan AU. Aetiology and antibiotic resistance patterns of community acquired urinary tract infections in JNMC Hospital Aligarh, In - dia. Ann Clin Microbiol Anti. 2007;6:4-10.

17. Mahesh E, Ramesh D, Indumathi VA. Complicated urinary tract infection in a tertiary care center in South India. Al Ameen J Med Sci. 2010;3(2):120-7.

18. Yengkokpam C, Ingudam D. Antibiotic susceptibility pattern of urinary isolates in Imphal, Manipur, India. Nepal Medical College J. 2007;9(3):170-2.

19. Sahm D, Thomsbery C, Mayfield D, Jones M, Karlowsky J. Multidrug resistant urinary tract isolates of escherichia coli: prevalence and patient demographic in the United States in 2000. Antimicrobial Agents and Chemotherapy. 2001;45(5):1402-6.

20. Okonofua EEA, Okonofua BN. Incidence and pattern of asymptomatic bacteriuria of pregnancy in Nigerian Women. The Nigerian Medical Practitioner. 1989;17:354-8.

21. Chhetri PK, Rai SK, Pathak UN. Retrospective study of urinary tract infection at Nepal Medical College Teaching Hospital, Kathmandu. Nepal Medical College J. 2001;3:83-5.

22. Rai CK, Pokhrel BM, Sharma AP. A prospective study of antibiotic sensitivity profile of the organisms associated with clinical infections among the patients attending TU teaching hospital. J Nepal Assoc Med Laboratory Sci. 2001;3:13-6.

23. Kumamoto Y, Tsukomoto T, Hirose T. Comparative studies on activities of antimicrobial agents against causative organisms isolated from patients with urinary tract infections. The $\mathrm{J}$ Antibiotics. 1998;51(2):112-29.

24. Kumari N, Ghirmire G, Magar JK, Mohapatra TM, Rai A. Antibiogram pattern of isolates from UTI cases in Eastern Part of Nepal. Nepal Medical College Journal. 2005;7(2):116-8. 
25. Vromen M, Vandervan AJ, Knols A, Sttob- beringh EE. Antimicrobial resistance patterns in urinary isolates from nursing home residents. Fifteen years of data reviewed. J Antimicrob Chemother. 1999;44(1):113-6.

26. Bajaj JK, Karyokarte RP, Kulkarni JD, Deshmukh AB. Changing aetiology of urinary tract infections and emergence of drugs resistance as a major problem. The J Com Dise. 1999;31(3):181-4.

Cite this article as: Arora G, Kaur P, Agrawal D.

Urinary tract infection in women of rural population

of Haryana: a rising problem. Int J Reprod

Contracept Obstet Gynecol 2016;5:4470-4. 